\title{
Comparison of Laparoscopy-Assisted Gastrectomy and Conventional Open Gastrectomy with the Same Procedure in Early Distal Gastric Cancer
}

\author{
Libo Sun*, Zhenbo Shu, Yunxin Zhang, Dayong Ding, Yongchao Li \\ Department of Gastrointestinal Surgery, China-Japan Union Hospital, Jilin University, Changchun, China. \\ Email: *sunlibo0431@sina.com
}

Received November $12^{\text {th }}, 2012$; revised December $14^{\text {th }}, 2012$; accepted December $23^{\text {rd }}, 2012$

\begin{abstract}
Introduction: Laparoscopy-assisted gastrectomy (LAG) for early gastric cancer (EGC) was considered as a treatment with many advantages due to the application of laparoscopic equipment. The aim of this study was to compare the effect of use of laparoscopic equipment in blood loss, the number of harvested lymph nodes (HLNs), and complications between LAG and open gastrectomy (OG) for EGC. Methods: Patients received surgical treatment for early distal gastric cancer (EDGC) were retrospectively reviewed. Patients were classified into three groups by different operation methods: traditional open distal gastrectomy (ODG) group, laparoscopy-assisted distal gastrectomy (LADG) group, and open distal gastrectomy with assistance of laparoscopic equipment (ODGA) group. Results: Altogether 65 patients with EDGC received surgical treatment, including 20 cases of ODG, 22 of LADG, and 23 of ODGA. No lymph node metastasis was found in all patients. 25 (38.5\%) postoperative confirmed T2 were misdiagnosed as T1 preoperatively. Compared with ODG group, the blood loss was significantly reduced in LADG and ODGA groups (106.4 \pm 46.0 ; and $73.3 \pm$ $35.7 \mathrm{ml}$ vs. $250.5 \pm 65.1 \mathrm{ml}$ respectively; $P<0.01$ ), but the operation time was significantly longer in these groups $(231.0 \pm 34.5$, and $222.5 \pm 42.6 \mathrm{~min}$ vs. $128.5 \pm 22.3 \mathrm{~min}$ respectively; $P<0.01)$. No difference was found in the blood loss, operation time, the number of harvested lymph nodes and the types of gastrointestinal continuity reconstruction between LADG and ODGA groups. No difference was found in the postoperative complications among the three groups. Conclusions: Laparoscopic equipment might be the key factor in the reduction of blood loss and the delay of operation time for LADG. Application of laparoscopic equipment in open gastrectomy can be used as a training method to shorten learning curve for LAG beginners.
\end{abstract}

Keywords: Laparoscopic Assisted Gastrectomy; Early Gastric Cancer; Open Gastrecomy; Laparoscopic Equipment

\section{Introduction}

Laparoscopy-assisted gastrectomy (LAG) for early gastric cancer (EGC) was considered as a successful treatment method with many advantages, including smaller incision, lower blood loss, less pain, quick recovery, and short hospitalization [1-3]. Due to the application of postoperative pain control and fast track surgery [4,5], some postoperative parameters, such as pain extent, time to oral intake become much more subjective. However, operation time, blood loss, the number of harvested lymph nodes (HLNs), complications, and survival period remain as relatively objective data. Compared with open gastrectomy (OG), LAG has many advantages due to the application of laparoscopic surgery equipment, such as harmonic scalpel. The aim of this study was to compare the effect of use of laparoscopic equipment in blood loss,

${ }^{*}$ Corresponding author. operation time, the number of HLNs, and complications between LAG and OG operations for EGC.

\section{Methods}

\subsection{Patients}

Patients received surgical treatment for early distal gastric cancer (EDGC) in the gastrointestinal department of China-Japan Union Hospital, between April 2009 and March 2012, were retrospectively reviewed. Patients were classified into 3 groups by different operation methods: Traditional open distal gastrectomy (ODG) group, laparoscopy-assisted distal gastrectomy (LADG) group, and the group of open distal gastrectomy with assistance of laparoscopic equipment (ODGA). All operations were performed by the same therapy team, including one senior surgical operator, two senior assistants, and one camera assistant in LADG. The preoperative diagnosis was 
done by endoscopy, biopsy, endoscopic ultrasound, and enhanced computer tomography. The stage of disease was classified according to the UICC TNM classification (6th edition), and only the stage T1N0M0 and T1N1M0 before surgery were included in this study. In both LADG and ODGA groups, patients were fully informed about the two type operations, and they chose the surgical method by themselves voluntarily. Both LADG and ODGA methods were approved by the medical ethics committee of our hospital. Patients suitable for endoscopic mucosal resection, and patients with a history of upper abdominal operation were excluded from this study. The surgical outcome was focused on the operative time, blood loss, and complications.

\subsection{Anesthesia and Surgical Procedure}

\subsubsection{Anesthesia and Trocar Placement}

General anesthesia was administered to all the patients. Patients were placed in the supine position with two legs apart. A 12-mm trocar for laparoscopy was introduced at the umbilicus, and pneumoperitoneum at $10-13 \mathrm{mmHg}$ was induced with carbon dioxide. At $2 \mathrm{~cm}$ below the costal margin, another $12-\mathrm{mm}$ trocar was inserted at the left preaxillary line, to serve as a major hand port, followed by a $5-\mathrm{mm}$ trocar placed at the left midclavicular line parallel to the umbilicus as an assistant port of the operator. As accessory ports, at the contralateral site, one $5-\mathrm{mm}$ trocar was inserted at the right preaxillary line and $2 \mathrm{~cm}$ below the costal margin, and another $5-\mathrm{mm}$ trocar was inserted at the right midclavicular line parallel to the umbilicus. The operator stood on the left side of the patient, the first assistant stood on the patient's right, and the camera assistant stood between the patient's legs.

\subsubsection{Laparoscopy-Assisted Distal Gastrectomy with D2 Dissection}

For this procedure, removal of No. $4 \mathrm{sb}, 4 \mathrm{sa}$, and 10 lymph nodes were performed at first. Along the border of the transverse colon, the greater omentum was dissected, using the Ultracision-Harmonic Scalpel (Ethicon EndoSurgery Inc., Cincinnati, OH, United States). The double Hem-o-lok clips (Teleflex Medical RTP, NC, United States) was used to clamp the left gastroepiploic vessel at its origin, followed by cutting the gastrosplenic ligament along the edge of spleen. To remove the No. 6, $4 \mathrm{~d}$ and $14 \mathrm{v}$ lymph nodes, the right gastroepiploic vessel were exposed, clamped and cut. To dissect the No. $8 \mathrm{a}$ and 5 lymph nodes, the common hepatic artery was confirmed along the gastroduodenal artery, and then the right gastric artery was divided and cut at its origin, from the proper hepatic artery. In order to remove the lymph node of No. 9 and No. 7, the left gastric artery was cut from the celiac trunk, and the celiac trunk was skeletonized. The No. 11 lymph nodes were removed by skeletonizing the splenic artery from its origin to the end. The dissection of No. 1 and 3 lymph nodes was performed along the liver edge to the esophagogastric junction, including the resection of the lesser omentum. As the last step of lymph nodes dissection, the No. 12a lymph nodes were removed by skeletonizing the proper hepatic artery. After the completion of D2 dissection, an upper midline incision (about $5 \mathrm{~cm}$ ) was made to perform the distal gastrectomy and gastrointestinal continuity reconstruction with linear staplers in a Billroth I or Billroth II procedure.

\subsubsection{Open Distal D2 Gastrectomy with the Assistance of Laparoscopic Equipment}

The anesthetic techniques used were the same as those of the LAG group. Patients lay in the supine position, and the operator stood on the right side of the patient. An incision about $20 \mathrm{~cm}$ was made at the upper midline. The gastrectomy with D2 dissection and reconstruction were performed in the same manner as in LAG group with the assistance of Ultracision-Harmonic Scalpel and double Hem-o-lok clips.

\subsubsection{Conventional Open Distal D2 Gastrectomy}

This procedure was performed using the same procedure described as ODGA with conventional equipments without the assistance of laparoscopic equipments. The method of gastrointestinal continuity reconstruction was also the same with the above.

\subsection{Statistical Analysis}

The data of patient's age, body index, operation time, blood loss, and the number of HLNs were presented as $\chi^{ \pm}$ $\mathrm{s}$. Independent-sample $\mathrm{t}$ test was used to estimate differences in age, operation time, blood loss, and the number of HLNs among the three groups. Chi-square test was used to compare the differences in sex, stage, and complications. All statistical analyses were performed with SPSS software, version 11.0 (SPSS Inc., Chicago, United States).

\section{Results}

\subsection{Patients Characteristics}

Altogether 65 patients suffered from EDGC received surgical treatment. Twenty cases were performed with ODG between April 2009 and March 2010, the other 45 cases were performed with laparoscopic surgery equipment between April 2010 and March 2012, including 22 cases of LADG, and 23 cases of ODGA. The characteristics of patients, such as age, gender, body mass index $\left(\mathrm{kg} / \mathrm{m}^{2}\right)$, and post-operative pathological stage are listed in the Table 1, and no difference is found among groups. 
Table 1. Characteristics of patients.

\begin{tabular}{lcccc}
\hline & $\begin{array}{c}\text { ODG } \\
(\mathrm{n}=20)\end{array}$ & $\begin{array}{c}\text { LADG } \\
(\mathrm{n}=22)\end{array}$ & $\begin{array}{c}\text { ODGA } \\
(\mathrm{n}=23)\end{array}$ & $\begin{array}{c}P \\
\text { value }\end{array}$ \\
\hline $\begin{array}{l}\text { Male: Female } \\
\begin{array}{l}\text { Mean age } \\
\text { (years, mean } \pm\end{array}\end{array}$ & $13: 7$ & $15: 7$ & $14: 9$ & NS \\
$\begin{array}{l}\text { SD) } \\
\text { Body mass index }\end{array}$ & $34.23 \pm 6.35 \pm 11.2$ & $58.83 \pm 9.05$ & $51.86 \pm 13.8$ & NS \\
Post-operative pathological stage & $35.85 \pm 6.91$ & $33.72 \pm 6.13$ & NS \\
T1N0Mx & 12 & 15 & 13 & NS \\
T1N1Mx & 0 & 0 & 0 & \\
T2N0Mx & 8 & 7 & 10 & NS \\
\hline
\end{tabular}

ODG: traditional open distal gastrectomy; LADG: laparoscopy-assisted distal gastrectomy; ODGA: open distal gastrectomy with assistance of laparoscopic equipment; NS: no significance.

However, 25 (38.5\%) postoperative confirmed T2 were misdiagnosed as $\mathrm{T} 1$ preoperatively. No postoperative lymph node metastasis was found in all of the 65 patients.

\subsection{Operation Related Data}

Compared with ODG group, the blood loss was significantly reduced in both LADG and ODGA groups, but the operation time was significantly longer in both groups. Neither the blood loss nor the operation time was found different between LADG and ODGA groups. No difference was found in the number of harvested lymph nodes and the type of gastrointestinal continuity reconstruction in the three groups (Table 2).

\subsection{Postoperative Complication and Mortality}

Postoperative complications are listed in Table 3, including delayed gastric emptying $(\mathrm{n}=2)$, incision infection $(\mathrm{n}=4)$, pancreatic fistula $(\mathrm{n}=1)$, and anastomotic leakage $(n=1)$. No difference was found in the postoperative complications among the three groups. All complications were cured with nonoperative method. No mortality occurred in the three groups.

\section{Discussion}

In recent years, laparoscopic surgery was applied widely not only in EGC, but also in advanced gastric cancer. Despite the long term survival remains unclear, many reports suggested that LAG in advanced gastric cancer could get similar short term results with that in EGC, without increment of morbidity and mortality [6-8]. However, until now LAG was still mainly used in EGC especially for the initiation stage of LAG $[9,10]$. In this study, the number of HLNs was similar among the three groups, supporting the previous conclusions that LAG
Table 2. Operation data and reconstruction type of the three groups.

\begin{tabular}{lcccc}
\hline Variable & $\begin{array}{c}\text { ODG } \\
(\mathrm{n}=20)\end{array}$ & $\begin{array}{c}\text { LADG } \\
(\mathrm{n}=22)\end{array}$ & $\begin{array}{c}\text { ODGA } \\
(\mathrm{n}=23)\end{array}$ & $P$ value \\
\hline $\begin{array}{l}\text { Blood loss (ml) } \\
\text { Operation time } \\
(\mathrm{min})\end{array}$ & $1250.5 \pm 65.1$ & $106.4 \pm 46.0^{*}$ & $73.3 \pm 35.7^{*}$ & $<0.01$ \\
HLNs & $15.6 \pm 5.6$ & $16.2 \pm 8.4$ & $12.7 \pm 8.8$ & $\mathrm{NS}$ \\
Reconstruction type & & $231.0 \pm 34.5^{*}$ & $222.5 \pm 42.6^{*}$ & $<0.01$ \\
Billroth I & 11 & 12 & 10 & $\mathrm{NS}$ \\
Billroth II & 9 & 10 & 13 & $\mathrm{NS}$ \\
\hline
\end{tabular}

ODG: traditional open distal gastrectomy; LADG: laparoscopy-assisted distal gastrectomy; ODGA: open distal gastrectomy with assistance of laparoscopic equipment; HLNs: the number of harvested lymph nodes; Significant difference was found between ODG and ( LADG + ODGA), no difference was found between LADG and ODGA; NS: no significance.

Table 3. Postoperative complications in the three groups.

\begin{tabular}{lcccc}
\hline Complications & $\begin{array}{c}\text { ODG } \\
(\mathrm{n}=20)\end{array}$ & $\begin{array}{c}\text { LADG } \\
(\mathrm{n}=22)\end{array}$ & $\begin{array}{c}\text { ODGA } \\
(\mathrm{n}=23)\end{array}$ & $P$ value \\
\hline $\begin{array}{l}\text { Delayed gastric } \\
\text { emptying }\end{array}$ & 0 & 1 & 1 & \\
Incision infection & 2 & 1 & 1 & \\
Pancreatic fistula & 0 & 0 & 1 & \\
Anastomotic leakage & 0 & 1 & 0 & \\
Total (\%) & $2(10 \%)$ & $3(13.6 \%)$ & $3(13.0 \%)$ & $\mathrm{NS}$ \\
\hline
\end{tabular}

ODG: traditional open distal gastrectomy; LADG: laparoscopy-assisted distal gastrectomy; ODGA: open distal gastrectomy with assistance of laparoscopic equipment; NS: no significance.

for early gastric cancer could get enough lymphadenectomy, and therefore could be considered as a safe and effective method for EGC [11]. This study showed that $25(38.5 \%) \mathrm{T} 2$ was misdiagnosed as $\mathrm{T} 1$ preoperatively, indicating that both CT and EUS had a lower sensitivity in differentiation between $\mathrm{T} 1$ and $\mathrm{T} 2$, and perhaps the experience of radiologist might influence the classification of $\mathrm{T}$ stage. According to the postoperative pathological results, no lymph node positive case was found in any of the enrolled cases. The reason for this unexpected result might be due to the fewer enrolled number of patients, and on the other hand, the micro-metastasis examination had not been a routine test method in our hospital. For obvious lymph node positive cases, close follow up was strongly commended [12].

Compared with traditional open gastrectomy, one of the obvious advantage of LAG is the reduction of blood loss $[3,13]$, which may be due to the application of laparoscopic equipment. The decrease of the blood loss in both LADG and ODGA groups suggested that the use of harmonic scalpel might be the key factor in reducing the bleeding amount during operation. Though no dif- 
ference was found between the LAG and ODGA groups, the amount of bleeding in LADG group is still relatively higher than that of OADG group. This may be due to the less experience in LADG technique, and on the other hand, bleeding control is relatively easy in OADG operation. Clear operation field is another obvious advantage of LAG operation, but the vision can be blurred easily by bleeding even though the amount of bleeding is not so much. Therefore, enough training is quite necessary to fully make use of the advantage of LAG. Finally, the use of harmonic scalpel might be another main reason for longer operation time. This study suggested that the application of laparoscopic equipment in open gastrectomy not only reduced the blood loss, but also shortened the learning curve for a LAG beginner. It can be used as a training method for LAG learners.

The safety of LAG should be considered as the first priority, therefore, both the open gastrecomy experience and excellent laparoscopic skill is essential for successful treatment with LAG. To overcome the learning curve, establishment of a perfect education system and team participation training course is very necessary [14-16]. Surgeons with much experience of open gastrectomy and laparoscopic surgery could perform LADG feasibly and safely $[17,18]$. In this study, D2 was successfully performed in all of the patients, without increment of the postoperative morbidity and mortality. To get a better result, all members in our operation team have had received LAG training course before the beginning of laparoscopic surgery. Besides the experience of open gastrectomy for cancer, the senior surgical operator also has other experiences in laparoscopic surgery including cholecystectomy, appendectomy, colectomy, and rectectomy prior to the initiation of LAG for cancer, we have performed more than 50 cases of LAG for benign lesions. The assistant nurses also have received LAG training, and they have regulatory worked in the operation team for years.

In conclusion, our data suggested that laparoscopic equipment is the key factor in the reduction of blood loss and delay of operation time for LADG. Application of laparoscopic equipment in open gastrectomy can be used as a training method for LAG beginners.

\section{REFERENCES}

[1] T. Etoh, M. Inomata, N. Shiraishi and S. Kitano, "Minimally Invasive Approaches for Gastric Cancer-Japanese Experiences," Journal of Surgical Oncology, Vol. 13, 2012. doi: $10.1002 /$ jso. 23128

[2] J. H. Lee, C. K. Yom and H. S. Han, "Comparison of Long-Term Outcomes of Laparoscopy-Assisted and open Distal Gastrectomy for Early Gastric Cancer," Journal of Surgical Oncology, Vol. 23, No. 8, 2009, pp. 1759-1763.

\section{doi:10.1007/s00464-008-0198-0}

[3] D. Yakoub, T. Athanasiou, P. Tekkis and G. B. Hanna, "Laparoscopic Assisted Distal Gastrectomy for Early Gastric Cancer: Is It an Alternative to the Open Approach?" Journal of Surgical Oncology, Vol. 18, No. 4, 2009, pp. 322-333. doi:10.1016/j.suronc.2008.08.006

[4] Z. Zhu, C. Wang, C. Xu and Q. Cai, "Influence of PatientControlled Epidural Analgesia versus Patient-Controlled Intravenous Analgesia on Postoperative Pain Control and Recovery after Gastrectomy for Gastric Cancer: A Prospective Randomized Trial," Gastric Cancer, Vol. 18, 2012.

[5] H. J. Chen, J. L. Xin , L. Cai, Z. H. Tao, H. S. Yuan, C. H. Bing, et al., "Preliminary Experience of Fast-Track Surgery Combined with Laparoscopy-Assisted Radical Distal Gastrectomy for Gastric Cancer," Journal of Gastrointestinal Surgery, Vol. 16, No. 10, 2012, 1830-1839. doi:10.1007/s11605-012-1969-4

[6] K. H. Kim, M. C. Kim, G. J. Jung and H. H. Kim, "LongTerm Outcomes and Feasibility with Laparoscopy-Assisted Gastrectomy for Gastric Cancer," Journal of Gastric Cancer, Vol. 12, No. 1, 2012, pp. 18-25.

[7] M. Cui, J. D. Xing, W. Yang, Y. Y. Ma, Z. D. Yao, N. Zhang, et al., "D2 Dissection in Laparoscopic and Open Gastrectomy for Gastric Cancer," World Journal of Gastroenterology, Vol. 18, No. 8, 2012, pp. 833-839. doi:10.3748/wig.v18.i8.833

[8] H. Sato, M. Shimada, N. Kurita, T. Iwata, M. Nishioka, S. Morimoto, et al., "Comparison of Long-Term Prognosis of Laparoscopy-Assisted Gastrectomy and Conventional Open Gastrectomy with Special Reference to D2 Lymph Node Dissection," Surgical Endoscopy, Vol. 26, No. 8, 2012, pp. 2240-2246. doi:10.1007/s00464-012-2167-x

[9] Y. K. Zeng, Z. L. Yang, J. S. Peng, H. S. Lin and L. Cai, "Laparoscopy-Assisted versus Open Distal Gastrectomy for Early Gastric Cancer: Evidence from Randomized and Nonrandomized Clinical Trials," Annals of Surgery, Vol. 256, No. 1, 2012, pp. 39-52. doi:10.1097/SLA.0b013e3182583e2e

[10] S. J. Yang, E. J. Ahn, S. H. Park, J. H. Kim and J. M. Park, "The Early Experience of Laparoscopy-Assisted Gastrectomy for Gastric Cancer at a Low-Volume Center," Journal of Gastric Cancer, Vol. 10, No. 4, 2010, pp. 241-246. doi:10.5230/jgc.2010.10.4.241

[11] Y. Liang, G. Li, P. Chen, J. Yu and C. Zhang, "Laparoscopic versus Open Gastrectomy for Early Distal Gastric Cancer: A Meta-Analysis," ANZ Journal of Surgery, Vol. 81, No. 10, 2011, pp. 673-680. doi:10.1111/j.1445-2197.2010.05599.x

[12] S. E. Lee, J. H. Lee, M. C. Kook, J. S. Yoo, K. W. Ryu, J. S. Lee, et al., "T2 or Greater Disease but Were Diagnosed Preoperatively with Early Gastric Cancer," Hepatogastroenterology, Vol. 55, No. 88, 2008, pp. 2282-2286.

[13] H. Ohtani, Y. Tamamori, K. Noguchi, T. Azuma, S. Fujimoto, H. Oba, et al., "A Meta-Analysis of Randomized Controlled Trials That Compared Laparoscopy-Assisted and Open Distal Gastrectomy for Early Gastric Cancer, Journal of Gastrointestinal Surgery, Vol. 14. No. 6, 2010, 
pp. 958-964. doi:10.1007/s11605-010-1195-x

[14] M. Tokunaga, N. Hiki, T. Fukunaga, A. Miki, S. Ohyama, S. Miyata, et al., "Learning Curve of Laparoscopy-Assisted Gastrectomy Using a Standardized Surgical Technique and an Established Educational System," Scandinavian Journal of Surgery, Vol. 100, No. 2, 2011, pp. 86-91.

[15] T. Kinoshita, E. Kanehira, M. Matsuda, S. Okazumi and R. Katoh, "Effectiveness of a Team Participation Training Course for Laparoscopy-Assisted Gastrectomy," Surgical Endoscopy, Vol. 24, No. 3, 2010, pp. 561-566. doi:10.1007/s00464-009-0607-z

[16] M. G. Kim, K. C. Kim, J. H. Yook, B. S. Kim, T. H. Kim and B. S. Kim, "A Practical Way to Overcome the Learn- ing Period of Laparoscopic Gastrectomy for Gastric Cancer," Surgical Endoscopy, Vol. 25, No. 12, 2011, pp. 38383844. doi:10.1007/s00464-011-1801-3

[17] C. H. Yoo, H. O. Kim, S. I. Hwang, B. H. Son, J. H. Shin and H. Kim, "Short-Term Outcomes of laparoscopic-Assisted Distal Gastrectomy for Gastric Cancer During a Surgeon's Learning Curve Period," Surgical Endoscopy, Vol. 23, No. 10, 2009, pp. 2250-2257. doi:10.1007/s00464-008-0315-0

[18] J. H. Han, H. J. Lee, Y. S. Suh, D. S. Han, S. H. Kong and H. K. Yang, "Laparoscopy-Assisted Distal Gastrectomy Compared to Open Distal Gastrectomy in Early Gastric Cancer," Digestive Surgery, Vol. 28, No. 4, 2011, pp. 245-251. doi:10.1159/000328658 